\title{
Carlos Altamirano: los comienzos y la cadencia de las escrituras
}

\author{
Gonzalo Aguilar \\ Universidad de Buenos Aires / CONICET
}

Entré en la carrera de letras de la Universidad de Buenos Aires en 1983. Creo que no necesito explicar por qué ese fue un año tan especial. El retorno de la democracia también se vivía en las aulas y nosotros (estudiantes que habíamos entrado a la carrera por haber leído a Girondo o a Borges, en el mejor de los casos), asistíamos, sin mucha información, al retorno de los profesores que habían sido expulsados durante la dictadura: Noé Jitrik, Enrique Pezzoni, Ramón Alcalde, Beatriz Sarlo, Josefina Ludmer, Nicolás Rosa, David Viñas y muchos otros fueron los nombres que empezaron a sonar en esos años. A algunos los conocíamos por vagas referencias (recuerdo que a Viñas se lo podía ver en algún programa de televisión), a otros -en cambio- recién comenzábamos a descubrirlos. Como espectadores que entran a un cine y comienzan a percibir las siluetas poco a poco, así estábamos nosotros en ese momento. Cursábamos introducción a la literatura con Delfín Leocadio Garassa (todavía no se había armado la cátedra iniciática de Enrique Pezzoni), íbamos a las marchas y ya comenzábamos a consumir, caótica y desmesuradamente, la teoría, ese ídolo al que aprenderíamos a brindarle una reverencia casi religiosa y que aún al día de hoy sigue recogiendo nuevas víctimas sacrificiales. El post-

estructuralismo francés, el textualismo, Roland Barthes, Michel Foucault, Jacques Derrida y otros nombres que sonaban para nosotros por primera vez pero que tenían una larga historia como Lukács o Adorno (Benjamin todavía no había hecho su entrada triunfal, que creo fue poco después). En su mayor parte eran libros que había editado Siglo XXI, Fondo de Cultura Económica u otras editoriales antes de la dictadura, por lo que teníamos la sensación de retomar una carrera de postas que había sido violentamente interrumpida.

Afortunadamente, la compilación Teoría de conjunto de la revista Tel Quel que había editado Seix Barral se encontraba en oferta en las librerías y nosotros podíamos devorar esos artículos de fines de los sesenta como si hubiesen sido escritos para entender la reapertura democrática, la crítica, la literatura o lo que fuera. "Pluralismo" era una de las palabras clave que servía tanto para la relación entre sociedad civil y Estado como para leer novelas y poemas. La consigna de que no había fuera de texto, que podía extraerse de los telquelianos o de Derrida, era -entre los estudiantes- una expresión del giro lingüístico que era ya un fenómeno mundial. El textualismo, además del perfume de la teoría francesa, tenía la ventaja de desacreditar cualquier tipo de autoritarismo y permitía rescatar la especificidad no como declinación de la autonomía, sino como un modo de crítica y resistencia. Comencé a realizar mi tesis sobre poesía concreta brasileña bajo el influjo de los astros post-estructuralistas y me disponía -como escribió Foucault en su polémica con Derrida- a una drástica "reducción de las prácticas discursivas a las trazas textuales". ${ }^{1}$

La cátedra de Beatriz Sarlo no estaba en el primer tramo de la carrera -todavía no se había hecho la reforma del programa de la carrera de 1987 que es el que sorprendentemente aún rige hoy-, pero ya llegaban rumores de pasillo de su importancia y sospecho que fue por esta razón que llegué a Literatura/Sociedad de Sarlo y Altamirano, publicado por Hachette en 1983, libro con el que me habría topado antes o después, porque era de lectura obligatoria. La tradición de lectura que invocaba este libro no era la del textualismo -más bien estaba en polémica con él-, pero tampoco era la de una sociología de la literatura. La invención de la palabra sociocrítica (que proponían los autores) quería dar cuenta de esta doble incomodidad, tanto con las lecturas inmanentes que hacían los herederos de Tel Quel como con una sociología reduccionista. El libro de Sarlo y Altamirano

\footnotetext{
${ }^{1}$ Historia de la locura en la época clásica, México, FCE, 1967, vol. 2, p. 371.
} 
contaba con una serie de antídotos que le permitían ubicarse entre estas dos corrientes sin caer en lo insípido: por un lado la presencia de Roland Barthes, que recordaba siempre la importancia del placer en la lectura crítica, la dimensión significativa de los detalles y una lectura del realismo en clave semiológica antes que referencial. Por otro, la presencia de nuevas referencias teóricas como Pierre Bourdieu o Raymond Williams: el marxismo heterodoxo de Williams permitía abandonar la simplificadora separación entre estructura y superestructura y se complementaba con las herramientas sociológicas de Bourdieu que daban lugar a funcionamientos particulares (con el concepto de campo) sin inmolarlos en el altar de la "totalidad" o en la determinación de la "última instancia económica".

En cualquier tesis -en tanto bildungsroman académico- pueden detectarse las cicatrices de la guerra que entablamos con nuestra propia formación y modos de leer. En el caso de mi investigación sobre poesía brasileña, la tesis se fue desplazando de la lectura textualista que me había marcado en mis años de estudiante a un intento de sociocrítica. Con el tiempo pude comprobar que mi experiencia no había sido solitaria o única (raramente las experiencias lo son), sino que ese mismo recorrido o esa marca - esa herida de guerra- podía percibirse en otros trabajos. Me animaría a decir que la huella de Literatura/Sociedad es la más fuerte en las tesis producidas en la academia argentina de los noventa. Para no hablar de la investigación sobre el diario Crítica de Sylvia Saitta (que había entrado directamente por la puerta de la sociocrítica), pienso en los libros de crítica literaria de Claudia Gilman sobre los debates latinoamericanos de los años sesenta, de Alejandra Laera sobre los orígenes de la novela argentina, o de Claudia Torre sobre la Conquista del Desierto. Mucho más fuerte fue la presencia de Literatura/Sociedad en la historia del arte: el cambio profundo de las últimas décadas no se hubiera dado sin el magisterio de Gastón Burucúa, es cierto, pero sería ininteligible sin el libro de Sarlo y Altamirano (pienso en los trabajos de Andrea Giunta, Marita García, Laura Malosetti Costa, Isabel Plante, Viviana Usubiaga y Silvia Dolinko entre muchos otros). ¿Qué es lo que traía ese libro, entonces? Con una apuesta pedagógica que Altamirano y Sarlo habían aprendido con Boris Spivacow en el Centro Editor de América Latina y que Carlos había continuado con la cátedra de Pensamieno Argentino en la UBA, con Prismas, con los encuentros de historia intelectual en el Ravignani, con la Universidad de Quilmes, Literatura/ Sociedad, con su falsa apariencia de manual, venía a decir cosas muy importantes. En primer lugar, traía un concepto clave del retorno de la democracia y que iba a experimentar más transformaciones: me refiero al concepto de cultura. Quizá ningún concepto sufrió una transformación tan profunda en los años ochenta (además del de democracia) y es evidente que para Carlos es una cuestión tan actual que no se priva de redefinirla en Estaciones, al escribir que la cultura "resumía la referencia a los sistemas simbólicos, a las prácticas de producción de significados y al campo de los hechos investidos de significación, de los textos a los rituales". ${ }^{2}$ Por otro lado, otro concepto importante que era una preocupación de ese momento es el de historicidad, y acá no puedo dejar de pensar en el texto de Foucault sobre Nietzsche que no casualmente Oscar Terán colocó al principio de su antología El discurso del poder, de $1983 .^{3}$ Pero sin duda lo más importante es que el libro nos invitaba a sacar la vista de los textos para observar todo un entramado de actores culturales, instituciones, ideologías y prácticas. Sobre todo las prácticas, no lo que se llamaba en la jerga militante la praxis, mantra singular y abstracto, siempre subordinado a la idea, sino el conjunto de haceres situados con los que interactuamos y nos plantean problemas.

Había allí una sociocrítica pero con la suficiente sensibilidad literaria como para dar el salto sin pérdidas sustanciales. Una sensibilidad que se ve en cómo Carlos trabaja con tópicos literarios del siglo XIX en Estaciones: la llegada del provinciano a la ciudad, las lecturas en desavenencia con el dictum paterno, la entrada en grupos de conspiración política y, sobre todo, además de las inclusiones en parte previsibles de Stendhal y Pavese, de Viñas y Auerbach, el inesperado papel de María Rosa Lida (Estaciones, p. 72) que habla justamente de la opacidad del lenguaje literario que nunca es secundario o accesorio en una cultura.

\footnotetext{
${ }^{2}$ Carlos Altamirano, Estaciones, Buenos Aires, Ampersand, 2019, p. 120.

${ }^{3}$ Michel Foucault, El discurso del poder, prólogo y edición de Oscar Terán, Buenos Aires, Folios, 1983.
} 
Hay un núcleo, entonces, una sensibilidad que puede haber quedado en un segundo plano en algún momento de su trayectoria, pero que siempre tiene que ver con un saber leer. En el capítulo "La lectura docta", Carlos cuenta cómo conoció a Saer, cómo lo impactaron sus relatos y la convicción de Saer de que estaba destinado a ser un gran escritor. Cuando se publica su novela Responso, Carlos dice que redactó "una nota breve pero entusiasta" (Estaciones, p. 88). Se la envió a su amigo Gerardo Pisarello, quien la acercó a la revista dirigida por Juan José Manauta: Hoy en la cultura. El primer texto publicado de Carlos salió en el número 21, de julio de 1965, y se titula "Realismo sustancial y voluntad polémica". Obviamente, como se imaginarán, estoy tentado a leerlo -aunque no pueda dejar de reconocer cierta violencia retrospectiva en esta interpretación- como un beginning en la línea de Edward Said. Además, Carlos no reproduce en su libro ningún pasaje de su reseña y supongo que tampoco le interesa hacerlo, dado que la reseña - más si quien la escribe es alguien que todavía no se hizo un nombre- suele ser un género ingrato. Sin embargo, tal vez tenga su valor leerla acá.

Como recordarán, Responso -"novela infravalorada e infraleída" en palabras de Beatriz Sarlo- ${ }^{4}$ cuenta la historia de Barrios, un dirigente del sindicato de prensa de la época peronista que es despojado de su cargo de un modo humillante en 1955. Barrios se separa de su esposa, se entrega al juego y pierde lo poco que tiene (entre otras cosas, la máquina de escribir que le había prestado su ex-mujer).

Una aguda conciencia del lenguaje, de sus posibilidades expresivas, penetraba los cuentos del primer libro de Juan José Saer, En la zona. Esa preocupación se mantiene en Responso, pero la inquietud moral que fermentaba en aquellas ficciones ha ganado en lucidez. En un mundo novelesco cargado de significaciones políticas y sociales, articula personajes y vicisitudes, a través de un ritmo narrativo muy bien elaborado. La voluntad de aferrar la realidad y develar su sentido, sobre todo mediante la asunción de nuestro pasado reciente, vincula a Saer al grupo más empeñoso entre los escritores argentinos

\footnotetext{
${ }^{4}$ Zona Saer, Santiago de Chile, Universidad Diego Portales, 2016.
}

jóvenes. En este caso la historia es el peronismo, la historia registrada, vivida, a nivel de una experiencia individual sin brillo pero preñada de implicaciones, la historia que aun alojada en el pasado del protagonista, se convierte en el eje de sus actos y sus elecciones.

El periodista Alfredo Barrios adhiere al peronismo; sin embargo, su adhesión eufórica y sincera es sentimental y no el resultado de una iniciativa política. La precariedad de esta decisión se pone a prueba cuando, en septiembre del 55, la política irrumpe, incomprensible, para Barrios: una revancha sin sentido, el fin de una ilusión, la incapacidad de superarla. Los hechos lo desbordan, apela a salidas imaginarias y se margina. La breve jornada de Barrios a que asistimos, y que ocupa la mayor parte de la novela, es abrumada por este pasado, soportado, sufrido como inercia. Es sólo la reiteración de los gestos falsos, las mentiras miserables de todos los pequeños actos con que ha pretendido substituir la ausencia de una voluntad y de un juicio lúcido que lo arraigara en la vida.

La progresión del protagonista ha sido construida con coherencia por Saer, quien narra sus dilemas y vicisitudes sin retóricas. Un tempo pausado, acentuado por el pulso verbal, de tono por momentos casi coloquial, consiente la indicación de matices y de alternativas que otorgan alta sugestión al relato. En este sentido es ejemplar el primer capítulo en que la repetición de ciertos motivos consigue una cadencia de gran eficacia poética. El resto de los personajes que integran el mundo de la novela, han sido concebidos a través de rasgos concretos. Con pocos datos Saer obtiene perfiles que un ajustado manejo del diálogo le permite enriquecer.

La búsqueda de un realismo sustancial y la voluntad polémica, que indudablemente mueven a este escritor santafecino, han logrado estructurar una obra valiosa, ubicada en la línea de nuestra mejor tradición narrativa. Por otra parte la preocupación por el rigor expresivo nos indica que comienza a superarse cierto malentendido acerca de lo que debe ser una literatura nacional-popular, impensable sin la conquista de un lenguaje literario propio. ${ }^{5}$
${ }^{5}$ Carlos Altamirano, "Realismo sustancial y voluntad polémica", en Hoy en la Cultura, $\mathrm{n}^{\circ} 21$, Buenos Aires, julio de 1965, p. 16. 
Es interesante que Carlos coloca el concepto de realismo sustancial en un momento en que todavía se discuten los residuos del realismo socialista. De hecho, hay una nota de Roger Garaudy anunciada en tapa como "Roger Garaudy y el realismo socialista", en la que el crítico francés, por entonces miembro del Partido Comunista, habla de "realismo abstracto". En el capítulo que le dedica en Estaciones a Héctor Agosti y a su En defensa del realismo, vuelve sobre el concepto: "el realismo -escribe Carlosconstituía el término central de esa estética, término que, a su vez, podía integrarse en diferentes fórmulas para designar tipos y etapas históricas del realismo: 'realismo burgués', 'realismo crítico', 'realismo socialista', etc.". O sea que el problema no era tanto el realismo ("no hay arte auténtico que no sea realista", escribe Garaudy) sino el atributo. Carlos, que seguramente no desconocía que la poética de Saer se había forjado en discusiones con el Partido y sus posiciones dogmáticas, propone el concepto de "realismo sustancial". Más allá de que no hay un desarrollo que permita vislumbrar los alcances de este atributo, no es menor que Altamirano haya decidido entrar en un debate bastante encarnizado a partir de la lectura de Saer. Tal vez haga referencia a lo que la literatura de Saer ya permite vislumbrar: que el problema del realismo no es de representación sino de conocimiento y que eso es lo que intenta expresar el atributo "sustancial", término de larga tradición filosófica. Me gusta imaginar a un Carlos joven mientras lee la novela, levemente disgustado con ese personaje viscoso que es Barrios pero con quien coincide cuando percibe que "lo verdadero, lo real" es "una cosa turbia e incierta". ${ }^{6}$ Sin poder identificarse con la "muchedumbre" (así describe la novela a los partidarios de la llamada Revolución

Libertadora), pero tampoco con Barrios (a quien Altamirano desprecia por su "inercia", por su "ausencia de voluntad" y la falta de un "juicio lúcido"), la reseña opta por un apego al lenguaje como lugar en el que se sedimenta una visión, una voluntad, lo social, en definitiva, una cultura. De hecho, la reseña habla de una "aguda conciencia del lenguaje", de "la preocupación por el rigor expresivo" y, en un pasaje clave, "una

${ }^{6}$ Juan José Saer, Responso, Buenos Aires, CEAL, 1983, p. 145 . cadencia de gran eficacia poética”. ¿Qué sería la cadencia? ¿Qué sería el "pulso verbal"? Yo me permito ser arbitrario y decir que lo que ya está acá, in nuce, es que el lenguaje, lo que después con Bourdieu llamaría "dimensión simbólica", es tan material, tan estructural o infraestructural como cualquier otra dimensión social. La dimensión material (la historia del peronismo reciente) y la simbólica se presuponen recíprocamente.

Al final de la breve reseña, Carlos coloca audazmente a Saer dentro de lo que él mismo denomina "literatura nacional-popular", con ecos evidentes de Antonio Gramsci. Lanzar ese epíteto, y no para hablar de Viñas o de Gorki sino para referirse a un escritor que solo llevaba publicados dos libros y tenía menos de 30 años, era temerario. Sin duda, puede leerse ahí un guiño a Agosti y también al Juan Carlos Portantiero de Realismo y realidad en la narrativa argentina, que había sido editado pocos años antes, en 1961, y que en el comienzo inserta una larga cita de Gramsci. El problema aparece muchas veces en Estaciones: el "divorcio entre los intelectuales y el pueblo-nación” (p. 62), la "tesis del divorcio" (p. 78), como la denomina, podría saldarse con un nuevo tipo de realismo. ¿Qué le hacía suponer a Carlos que Saer, justamente Saer, un escritor de una rara sofisticación en ese momento, podría saldar ese divorcio? ¿Hay que leerlo como el intento de trazar un diagnóstico acertado o más bien como un guiño polémico a las disidencias que se daban dentro del comunismo? ¿O las dos cosas?

Visto con el paso del tiempo y para seguir hablando de beginnings, es curioso que ahí esté Saer, lo que no es menor. Que la primera reseña haya sido justamente sobre Saer significa que hay una escritura que no puede ser ignorada. Relacionar a Saer con el realismo (el ideologema de época) era una indicación de que a veces no se trata de superar los problemas (ese hegelianismo generalizado) sino de ver si los problemas no están mal planteados.

En las autobiografías intelectuales (y también tal vez en cualquier autobiografía) hay un momento clave, y que aquí voy a nombrar con una palabra que está en Estaciones en la página 34: el torbellino. "Fue como un torbellino y yo me sumergí en él”. En una autobiografía ese es un momento muy preciso y muy intenso. Es el momento de la iniciación, la ebriedad, el vértigo, la pérdida de sí, del entusiasmo sin límites. Es 
como si el sujeto entrara en una zona de turbulencia en la que se pierde y con cuyos materiales deberá construir -no de un modo libre sino condicionado- su subjetividad futura. Como para muchos intelectuales y jóvenes de su generación, fue la lucha entre escuela laica y libre. Como en el caso de Halperin Donghi, se trata de una autobiografía intelectual: la relación con el acontecimiento nunca es inmediata y una suerte de Carlos fantasmático se sale del "torbellino", observa y especula sobre aquello que está sucediendo. Lejos de los "ejercicios de ego-historia", Carlos avanza en una "especie de cofraternidad disidente" y nos entrega, para los críticos de la cultura, una zona, para usar una vez más un término saeriano. Como lo hizo con el grupo de Punto de Vista (pienso en Sarlo y, por supuesto, en María Teresa Gramuglio), los compañeros de Prismas, hay ahí una zona, no de la ficción sino de la crítica, contra un reduccionismo: ya que la historia previa y aun la dictadura, mostraban la necesidad de no hundir la escritura (literaria o crítica) en el torbellino de la política. O mejor aun: que en la "cadencia" de una escritura podía aguardarnos la fuerza de una política posible. 